\title{
Penentuan Kapasitas Mesin Dan Produktifitas Operator Dengan Menggunakan Metode Flow Material Information Chart Dan Tabel Standar Kerja Di Lini 3 PT. Garudafood
}

\author{
Adhika Nandiwardhana ${ }^{1}$, dan Ilham Priadythama ${ }^{2}$ \\ ${ }^{1)}$ Mahasiswa Program Studi Teknik Industri, Universitas Sebelas Maret \\ J1. Ir. Sutami 36A, Surakarta 57126, Indonesia \\ ${ }^{2)}$ Laboratorium Perencanaan DanPerancangan Produk, Program Studi Teknik Industri, Universitas Sebelas Maret \\ J1. Ir. Sutami 36A, Surakarta 57126, Indonesia
}

\begin{abstract}
Abstrak
Kualitas produksi dan performa perusahaan dapat ditingkatkan dengan mengurangi pemborosan yang ada di perusahaan. Dalam penelitian ini, metode yang digunakan adalah FMIC (Flow Material Information Chart) untuk menghitung kapasitas mesin, produktivitas operator dan TSK (Tabel Standar Kerja) untuk mengukur beban kerja operator. Hasil yang diperoleh dari penelitian ini adalah kapasitas mesin terbesar adalah mesin frying dengan jumlah $7935,75 \mathrm{~kg}$. Nilai produktivitas operator tertinggi adalah operator proses frying dengan jumlah $881,75 \mathrm{~kg} / \mathrm{orang}$. Nilai cycle time semua operator selalu lebih kecil atau sama dengan nilai takt time mesin sehingga kerja operator masih termasuk ke dalam kategori kerja ringan. Nilai not value work yang didapat untuk tiap operator selalu lebih besar daripada nilai value work. Kesimpulan yang didapat dari penelitian ini adalah diperlukan upaya untuk mengurangi jumlah operator atau menambah jumlah mesin packing. Selain itu perlu dibuat penutup untuk mesin molen di stasiun coating sehingga jumlah waste mentah dapat dikurangi.
\end{abstract}

Kata kunci: kualitas produksi. performa perusahaan. pemborosan. Flow Material Information Chart. Tabel Standar Kerja.

\begin{abstract}
The quality of production and company performance could be improved by reducing the waste of the company. The method used in this research is FMIC (Flow Material Information Chart) which calculated the engine capacity, operator productivity and SWT (Standard Working Table) which measured operator work load. The result of this research showed the biggest machine capacity was frying machine with the amount of 7935,75 kg. The highest productivity value of operators was the frying process operator with the amount of $881.75 \mathrm{~kg} /$ person. The cycle time value of all operators was always smaller or equal to the takt time value of the machine so that the operator's work was still included in the light work category. Not value work obtained for each operator was always greater than the value of work value. The conclusion of this research was the number of operators should be reduced or the number of packing machines should be increased. In addition a cover for the molen machine in the coating station should be made so that the amount of raw waste could be reduced.
\end{abstract}

Keywords: Quality of production. Company performance. Waste. Flow Material Information Chart. Standars Work Table.

\section{Pendahuluan}

PT. Garudafood Putra Putri Jaya Division Coated Peanuts adalah salah satu perusahaan berskala nasional yang bergerak dalam bidang food dan baverages yang terletak di Kota Pati, Jawa Tengah. Pada perusahaan, sistem produksi dibagi menjadi dua area yaitu Factory A dan Factory B. Factory A sebagian besar memproduksi makanan yang berbahan dasar dari kacang-kacangan seperti kacang atom, kacang telur, kacang panggang dan sebagainya, sedangkan untuk Factory $B$ memproduksi makanan yang berbahan dasar dari tepung misalnya Leo kripik kentang, Pilus, Gery toya-toya dan sebagainya. Untuk Memenuhi permintaan dan mendapat tempat pada pasar di dunia industri pangan, PT. Garudafood berusaha untuk selalu meningkatkan kualitas produksi dan performa perusahaan dalam berbagai aspek salah satunya dengan mengurangi pemborosan-pemborosan yang ada di perusahaan.

Terdapat 8 tipe pemborosan (muda) yaitu: over production (produksi berlebih), waiting (waktu menunggu), transportation (transportasi yang tidak perlu), over processing (memproses secara berlebih), excess inventory (persediaan yang berlebih), unnecessary movement (gerakan yang tidak perlu), defect 
(produk cacat), unused employee creativity (kreativitas karyawan yang tidak dimanfaatkan) (Taiichi Ohno, 2006). Untuk menunjukkan kedelapan pemborosan tersebut dapat dilakukan dengan menggunakan metode Kanban, TSK, FMIC, Total Productive Maintenance (TPM), SMED, Kaizen, 5S dan Heijunka (Kalpakjian, 2006).

Berdasarkan pengamatan langsung pada lini 3 di factory A yang memproduksi kacang telur, ditemukan indikasi terjadinya pemborosan yang ada di sistem produksi. Pemborosan yang ada di lini 3 dapat dilihat di beberapa stasiun yang ada ketika operator sedang melakukan kerja. Ada saatnya terdapat operator yang menganggur karena menunggu proses produksi lama dan ada juga kerja operator yang terlalu sibuk melakukan kerja. Hal ini disebabkan karena kurangnya keseimbangan antara jumlah operator yang diperlukan dengan kecepatan mesin yang bekerja. Dari pengamatan tersebut terlihat bahwa pada lini 3 terdapat permasalahan terkait dengan pemborosan. Oleh karena itu dilakukan penelitian yang bertujuan untuk melihat kondisi flow material dan kondisi kerja operator proses produksi di lini produksi 3 PT. Garudafood dengan menggunakan metode FMIC (Flow Material Information Chart) dan TSK (Tabel Standar Kerja).

\section{Metode Penelitian}

Metode FMIC (flow material information chart) adalah sebuah metode visual untuk memetakan jalur produksi dari sebuah produk yang di dalamnya termasuk material dan informasi dari masing-masing stasiun kerja. Flow material information chart ini dapat dijadikan titik awal bagi perusahaan untuk mengenali pemborosan dan mengidentifikasi penyebabnya. Menggunakan Flow material information chart berarti memulai dengan gambaran besar dalam menyelesaikan permasalahan bukan hanya pada proses-proses tunggal dan melakukan peningkatan secara menyeluruh dan bukan hanya pada proses-proses tertentu saja.TSK (Tabel Standarisasi kerja) adalah sebuah metode kerja agar bisa memproduksi se-efisien mungkin dengan urutan kerja dan cara pengerjaanya dalam waktu yang sudah ditetapkan, yang betul-betul sudah menjamin safety dan quality. Analisa dengan menggunakan Tabel Standarisasi Kerja (TSK) sehingga dapat diketahui cycle time, takt time, lead time dan loading time dari proses kerja.

Pengambilan data untuk pembuatan FMIC dilakukan pada bulan Juli-September 2013, sedangkan pengambilan data OEE (Overall Equipment Effectiveness) dan YWL (Yield, Waste, Loss) dilakukan dari tanggal 9 september 2013 sampai dengan 14 september 2013. Pengambilan data TSK dilakukan sebanyak 10 siklus dan pengambilan data Loading Chart dilakukan selama 1 shift (480 menit). Asumsi yang digunakan dalam penelitian ini adalah pada pengambilan data TSK menggunakan waktu siklus.

\section{Hasil dan Pembahasan}

Data yang akan digunakan diperoleh dari pengamatan di tiap stasiun kerja, dimulai dari stasiun stock preparation (mixing), stasiun coating, stasiun frying, dan stasiun packaging. Pada stasiun stock preparation (mixing) dilakukan proses mixing untuk pembuatan kanji dan pembuatan pasta dengan menggunakan mesin jus dan mesin fristam. Pada stasiun coating dilakukan proses coating dengan menggunakan mesin molen. Pada stasiun frying dilakukan proses frying dengan mesin frying. Pada stasiun packaging dilakukan proses packaging untuk 2 macam jenis packaging yaitu item TGPE dan TGF dengan mesin SVB 100 dan mesin SVB 150.

\section{Analisis Data Dengan Metode FMIC}

Analisis data dengan metode FMIC meliputi analisis nilai takt time, analisis nilai OEE, analisis yield, waste dan loss produksi.

\subsubsection{Nilai Takt time}

Perhitungan nila takt time dimulai dengan pengambilan data output dari masing-masing proses dan cycle time dari masing-masing proses kemudian diolah sehingga didapatkan hasil seperti dalam Tabel 1.

Tabel 1. Data Takt Time Tiap Stasiun Kerja

\begin{tabular}{|c|c|c|c|c|c|c|}
\hline Proses & & xing & Coating & Frying & $\mathrm{Pac}$ & ging \\
\hline Parameter & Mesin Jus & Mixer Fristam & Molen & Frying & $\begin{array}{c}\text { SVB } \\
100 \\
\end{array}$ & $\begin{array}{c}\text { SVB } \\
150 \\
\end{array}$ \\
\hline Jumlah mesin & 2 & 1 & 11 & 1 & 12 & 4 \\
\hline Takt time (menit/kg) & 0,0494 & 0,1940 & 0,5621 & 0,0536 & 1,0101 & 0,6127 \\
\hline Takt time total & 0,0247 & 0,1940 & 0,0511 & 0,0536 & 0,0842 & 0,1532 \\
\hline
\end{tabular}


Analisis takt time pada tiap mesin digunakan untuk melihat kondisi line balancing atau keseimbangan lini apakah seimbang atau tidak dengan banyaknya mesin yang ada di tiap stasiun. Dapat dilihat pada Tabel 1 bahwa terdapat perbedaan nilai takt time mesin yang signifikan di tiap stasiun produksi lini 3. Hal ini menunjukkan perlunya ada penyesuaian agar tidak terjadi kondisi bottle neck dalam proses produksi. Besar nilai takt time mesin frying dijadikan sebagai nilai takt time acuan karena apabila mesin frying mati maka proses produksi di seluruh stasiun produksi lini 3 akan berhenti bekerja. Proses penting lain yang harus menyesuaikan dengan proses frying adalah proses coating dan packaging karena proses-proses tersebut berlangsung terus menerus mulai dari awal jam kerja sampai akhir jam kerja sehingga rangkaian proses yang berjalan haruslah seimbang (balance). Sedangkan untuk proses yang lain yaitu proses pembuatan kanji dan pasta tidak terlalu banyak masalah dan dilakukan sesuai dengan kebutuhan. Dapat dilihat untuk satu mesin roasting tidak balance jika menggunakan satu mesin coating dan satu mesin packaging. Jika takt time coating lebih besar dari takt time mesin frying maka akan terjadi bottle neck antara proses coating dan frying. Jika takt time frying besarnya lebih kecil dan signifikan dari proses packaging maka akan terjadi menganggur di stasiun packaging.Dari perhitungan nilai takt time yang ada, jika digunakan 1 mesin frying maka mesin coating yang dibutuhkan adalah sebanyak 11 mesin, mesin SVB 100 yang digunakan sebanyak 16 mesin, dan mesin SVB 150 yang digunakan sebanyak 6 mesin. Hal ini dilakukan agar tidak terjadi kondisi bottle neck dalam proses produksi.

\subsubsection{Nilai OEE}

OEE digunakan untuk melihat tingkat produktivitas mesin di tiap-tiap stasiun kerja yang ada. Tabel 2 menunjukkan nilai OEE tiap mesin pada lini 3.

Pada stasiun stock preparation, nilai OEE pada proses pembuatan kanji relatif kecil yaitu 43,18\% karena proses pembuatan kanji dalam satu shift kerja hanya beroperasi 12-13 kali siklus, sedangkan nilai OEE pada proses pembuatan pasta hanya sebesar 1,07\% karena proses pembuatan pasta dalam satu shift kerja hanya beroperasi 3-4 kali siklus dimana tiap siklusnya hanya membutuhkan waktu sekitar 3-5 menit. Pasta dibuat sesuai kebutuhan atau permintaan dari stasiun coating, selebihnya mesin menganggur. Pada stasiun coating nilai OEE proses coating relatif tinggi yaitu 83,77\% karena proses coating dalam 1 shift beroperasi secara terus menerus tanpa henti. Proses coating baru dimulai pada jam 07.30 karena menunggu bahan kanji dan pasta selesai dibuat dari stasiun stock preparation dan diakhiri pada pukul 14.00 untuk memberi waktu kepada stasiun frying untuk menyelesaikan proses goreng papatan yang dihasilkan stasiun coating. Pada stasiun frying nilai OEE proses frying yaitu 88,59\%, Mesin frying beroperasi mulai dari jam 08.00 sampai dengan jam 15.00 dan jarang mengalami breakdown. Banyak waktu yang hilang di kategori down time loss yaitu wktu untuk proses setting dan cleaning selama proses produksi berlangsung dan beberapa menit untuk proses pergantian item produk. Pada stasiun packaging terdapat dua jenis item packaging yaitu item TGPE dan item TGF, dengan nilai OEE masing-masing untuk TGPE 83,44\% dan untuk TGF nilainya 70,51\%. Mesin SVB beroperasi full selama satu shift kerja jika terdapat sisa WIP yang belum terbungkus dari shift sebelumnya. Namun jika tidak ada sisa WIP dari shift sebelumnya, maka mesin baru beroperasi sekitar pukul 08.20 karena menunggu WIP matang dari proses frying. Banyak waktu yang hilang di kategori down time loss yaitu waktu untuk proses setting dan cleaning selama proses produksi berlangsung dan waktu istirahat. 
Tabel 2. Nilai OEE Tiap Mesin Lini 3

\begin{tabular}{|c|c|c|c|c|c|c|}
\hline & \multicolumn{6}{|c|}{ Grup A } \\
\hline & Kanji & Pasta & Coating & Frying & TGPE & TGF \\
\hline OEE & $31,60 \%$ & $0,72 \%$ & $78,98 \%$ & $83,93 \%$ & $84,05 \%$ & $62,25 \%$ \\
\hline \multirow[t]{3}{*}{ Production Efficiency } & $31,60 \%$ & $0,72 \%$ & $78,98 \%$ & $83,93 \%$ & $84,05 \%$ & $62,25 \%$ \\
\hline & \multicolumn{6}{|c|}{ Grup B } \\
\hline & Kanji & Pasta & Coating & Frying & TGPE & TGF \\
\hline OEE & $56,70 \%$ & $1,38 \%$ & $87,70 \%$ & $93,76 \%$ & $86,06 \%$ & $0,00 \%$ \\
\hline \multirow[t]{3}{*}{ Production Efficiency } & $56,70 \%$ & $1,38 \%$ & $87,70 \%$ & $93,76 \%$ & $86,06 \%$ & $0,00 \%$ \\
\hline & \multicolumn{6}{|c|}{ Grup C } \\
\hline & Kanji & Pasta & Coating & Frying & TGPE & TGF \\
\hline OEE & $54,07 \%$ & $1,44 \%$ & $88,98 \%$ & $93,00 \%$ & $82,39 \%$ & $74,63 \%$ \\
\hline \multirow[t]{3}{*}{ Production Efficiency } & $54,07 \%$ & $1,44 \%$ & $88,98 \%$ & $93,00 \%$ & $82,39 \%$ & $74,63 \%$ \\
\hline & \multicolumn{6}{|c|}{ Semua Grup Selama 1 Minggu } \\
\hline & Kanji & Pasta & Coating & Frying & TGPE & TGF \\
\hline OEE & $43,18 \%$ & $1,07 \%$ & $83,77 \%$ & $88,59 \%$ & $83,44 \%$ & $70,51 \%$ \\
\hline Production Efficiency & $43,18 \%$ & $1,07 \%$ & $83,77 \%$ & $88,59 \%$ & $83,44 \%$ & $70,51 \%$ \\
\hline
\end{tabular}

\subsubsection{Yield, waste dan loss produksi}

Analisis yield, waste dan loss digunakan untuk melihat sebarapa besar hasil produksi yang dihasilkan pada tiap stasiun dan seberapa besar produk cacat yang dihasilkan. Yield, waste dan loss setiap stasiun di lini 3 terlihat pada Tabel 3. Pada stasiun stock preparation proses pembuatan kanji dan pasta memiliki nilai yield $100 \%$. Hal ini disebabkan karena selama proses pembuatan kanji dan pasta tidak ada WIP yang hilang ataupun terbuang, sehingga jumlah input sama dengan jumlah output. Pada stasiun coating, proses coating memiliki nilai yield $98,34 \%$, waste $0,12 \%$ dan loss $1,67 \%$. Waste pada proses coating digolongkan kedalam waste mentah yaitu waste yang didapat dari sisa tepung yang telah digunakan selama proses coating ataupun papatan yang ditolak karena tidak memenuhi standar untuk masuk ke proses frying. Sedangkan nilai loss pada proses coating didapat dari jumlah tepung yang hilang ketika penaburan tepung ke mesin molen dalam proses coating. Pada stasiun frying, proses frying memiliki nilai yield $98,34 \%$, waste $1,05 \%$ dan loss $0,61 \%$. Waste pada proses frying digolongkan ke dalam waste matang yaitu WIP yang tidak sesuai standar. Misal kondisi WIP hasil frying menyatu atau 'nggembel', sedangkan loss pada proses frying disebabkan karena WIP kehilangan bobot akibat kandungan air yang hilang selama proses penggorengan papatan. Pada stasiun packaging terlihat proses packaging dari kedua jenis item hanya memiliki waste dan tidak menghasilkan loss. Waste dari packaging dalam bentuk waste roll. Waste roll didapat ketika dilakukan proses setting pada mesin SVB dimana ada beberapa roll yang terbuang agar penyesuaian kemasan produk dapat dilakukan.

Tabel 3. Yield, Waste dan Loss Tiap Stasiun

\begin{tabular}{lcccccc}
\hline & \multicolumn{7}{c}{ Yield, Waste dan Loss } \\
\cline { 2 - 7 } & Kanji & Pasta & Coating & Frying & TGPE & TGF \\
\hline Yield & $100 \%$ & $100 \%$ & $98,21 \%$ & $98,34 \%$ & $99,54 \%$ & $97,99 \%$ \\
Waste & $0,00 \%$ & $0,00 \%$ & $0,12 \%$ & $1,05 \%$ & $0,46 \%$ & $2.01 \%$ \\
Loss & $0,00 \%$ & $0,00 \%$ & $1,67 \%$ & $0,61 \%$ & $0,00 \%$ & $0,00 \%$ \\
\hline
\end{tabular}

\subsection{Analisis Data Dengan Metode TSK}

Analisis data dengan metode FMIC meliputi analisis TSK tiap operator dan analisis loading chart tiap operator.

\subsubsection{Analisis TSK Tiap Operator}

Analisis TSK dilakukan untuk melihat perbandingan antara nilai cycle time dan nilai takt time. Perbandingan tersebut digunakan untuk menentukan apakah kerja operator termasuk dalam kategori kerja berat atau dalam kategori kerja ringan (atau bahkan banyak menganggur). Tabel $\mathbf{4}$ menunjukkan nilai cycle time dan nilai takt time. Dapat dilihat operator bungkus WIP, operator ngebosi TGPE, operator ngebali TGPE, operator ngebosi TGF, operator ngerdusi TGF dan operator ngebali TGF memiliki nilai cycle time 
lebih kecil daripada nilai takt time, sehingga masing-masing operator dapat dikategorikan sebagai kerja ringan

Tabel 4. Cycle time dan Takt time Tiap Operator (detik)

\begin{tabular}{clcc}
\hline No & Job Desk & $\begin{array}{c}\text { Cycle time } \\
\text { (detik) }\end{array}$ & $\begin{array}{c}\text { Takt } \\
\text { time } \\
\text { (detik) }\end{array}$ \\
\hline 1 & Operator Bungkus WIP & 41 & 45,7 \\
2 & Operator Ngebosi TGPE & 12 & 18,18 \\
3 & Operator Ngebali TGPE & 88 & 109,09 \\
4 & Operator Ngebosi TGF & 15 & 23,53 \\
5 & Operator Ngerdusi TGF & 33 & 70,59 \\
6 & Operator Ngebali TGF & 31 & 70,59 \\
\hline
\end{tabular}

\subsubsection{Analisis Loading Chart Tiap Operator}

Analisis loading chart tiap operator digunakan untuk melihat seberapa banyak kerja operator yang termasuk ke dalam pekerjaan yang menghasilkan nilai tambah terhadap produk (value added) atau pekerjaan yang tidak menghasilkan nilai tambah terhadap produk (not value added). Loading chart tiap operator ditunjukkan oleh Gambar 1.

Dari Gambar 1 dapat diketahui bahwa operator kanji dan pasta 1 dan 3 memiliki nilai walk cukup besar karena ketika pengambilan data, operator sering berjalan bolak-balik dari area stock preparation gudang bahan baku untuk mengambil keperluan bahan baku, sedangkan operator kanji dan pasta 2 yang lebih jarang melakukannya memiliki nilai walk lebih kecil. Nilai not value work operator kanji dan pasta 1, 2 dan 3 besar karena proses mixing dilakukan oleh mesin sehingga operator sering menunggu.

Operator langsir WIP memiliki nilai not value work besar karena operator banyak menunggu kanji maupun pasta selesai dibuat dan siap dilangsir menuju ke stasiun coating. Selain itu, operator juga terkadang membantu pekerjaan operator pembuat kanji dan pasta yang bukan merupakan pekerjaan pokoknya. Operator setup mesin frying memiliki nilai not value work besar karena sebagian besar pekerjaan operator adalah mengawasi panel-panel kontrol mesin frying sambil duduk, sehingga untuk kategori walk bernilai 0 .

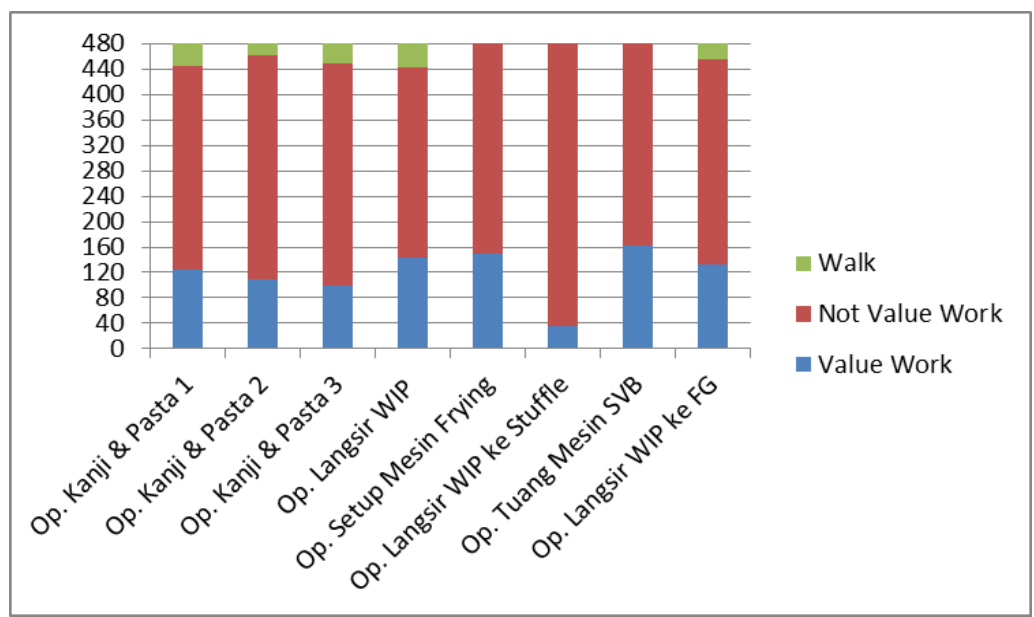

Gambar 1. Grafik Loading Chart Tiap Operator

Operator langsir WIP ke stuffle memiliki nilai not value work sangat besar karena pada dasarnya, pekerjaan operator langsir WIP ke stuffle tidak memberikan nilai tambah terhadap produk karena hanya sebatas mengangkut saja. Selain itu, operator sering sekali bertukar kerja dengan operator lain yaitu operator bungkus WIP sehingga operator langsir WIP ke stuffle lebih sering melakukan kerja yang bukan merupakan pekerjaan pokoknya. Operator tuang mesin SVB memiliki nilai walk nol karena operator hanya memindahkan kontainer dari konveyor langsung ke mesin SVB. Nilai not value work besar karena sebagian besar pekerjaan operator hanya menuang kontainer-kontainer berisi WIP ke mesin SVB dan selebihnya hanya menunggu WIP yang ada di mesin SVB habis terkemas. Operator langsir WIP kegudang FG memiliki not value work besar karena pada dasarnya, pekerjaan operator langsir WIP ke gudang FG tidak memberikan nilai tambah terhadap produk karena hanya sebatas mengangkut saja. Selain itu, operator sering sekali membantu kerja operator lain yaitu operator packing mesin SVB sehingga operator langsir WIP ke gudang FG lebih sering melakukan kerja yang bukan merupakan pekerjaan pokoknya. 


\section{Simpulan dan Saran}

Berdasarkan hasil pengolahan data dan analisis yang telah dilakukan, didapatkan bahwa kapasitas mesin terbesar adalah mesin frying dengan jumlah $7935,75 \mathrm{~kg}$. Nilai produktivitas operator tertinggi adalah operator proses frying dengan jumlah $881,75 \mathrm{~kg} /$ orang. Nilai cycle time semua operator selalu lebih kecil atau sama dengan nilai takt time mesin sehingga kerja operator masih termasuk ke dalam kategori kerja ringan. Nilai not value work yang didapat untuk tiap operator selalu lebih besar daripada nilai value work.

Masih adanya operator kerja packing dengan tingkat kerja ringan. Hal ini dapat dikondisikan dengan mengurangi jumlah operator atau dengan menambah jumlah mesin packing yang digunakan. Selain itu perlu dibuat penutup untuk mesin molen di stasiun coating sehingga jumlah waste mentah dapat dikurangi.

Perlu dilakukan penelitian lanjutan untuk mengetahui jumlah estimasi operator yang perlu dikurangi atau jumlah mesin yang perlu ditambahkan pada stasiun kerja frying dan coating sehingga dapat dicapai nilai yield $100 \%$.

\section{Ucapan Terima Kasih}

Terima kasih peneliti sampaikan pada PT. Garudafood baik kepada jajaran direksi yang telah memberikan kesempatan untuk melakukan penelitian maupun kepada karyawan lini 3 yang telah membantu selama pengambilan data untuk penelitian.

\section{Daftar Pustaka}

Anonim. (2014). Memperpendek Waktu Changeover dengan Teknik SMED. http://belajarlean.blogspot.com/2011/05/memperpendek-waktu-changeover-dengan.html

Anonim.(2014).Pengertian: Konsep dan Metode Kanban.

http://kamusindustri.blogspot.com/2012/06/pengertian-konsep-dan-metode-kanban.html

Anonim. (2013). Lean manufacturing basics. http://www.leanmanufacturingconcepts.com

Garudafood.N.d. Garudafood Group Company. http://www.garudafood.com/download/COMPANY_PROFILE_OF_GARUDAFOOD_G ROUP.pdf

J. Allen, C. Robinson, and D. Steward. (2001). Lean Manufacturing, a Plant Floor Guide. Total Systems Development, Inc.: 360-373.

Liker, Jeffrey K and David Meier. (2006). The Toyota Way Fieldbook. Jakarta: Erlangga

M. Rother and J. Shook. (1999), Learning to See, Value Stream Mapping to Create Value And Eliminate Muda (foreword by Jim Womack and Dan Jones), Version 1.2: 9 -19.

S. Kalpakjian and S. Schmid. (2006). Manufacturing Engineering And Technology, 5th edition, Prentice Hall: $1227-1228$.

Stephen L. Woehrle, LouayAbou-Shady. (2010). Using DynamicValue Stream Mapping and Lean Accounting. Box Scores to Support Lean Implementation, Minnesota State University:Mankato 